\title{
Lithospheric Mantle anisotropy of the Kaapval craton (South Africa) from lattice preferred orientation analysis
}

\author{
W. Ben Ismail*, D. Mainprice*, G. Barruol*, J. Boyd ${ }^{+}$, A.Vauchez*
}

* CNRS, Laboratoire de Tectonophysique, Université de Montpellier II, Place E. Bataillon, 34095 CEDEX 05, France. Email: walid@dstu.univ-montp2.fr

${ }^{+}$Carnegie Institution of Washington, 5241 Broad Branch Road NW, Washington, DC 20015

Seismic tomography and petrological data on mantle xenoliths suggest a thick lithosphere extending down to at least $200 \mathrm{Km}$ depth beneath the Kaapval craton. Seismic anisotropy at depth is controlled by crystal lattice preferred orientation (e.g., Barruol and Mainprice, 1993) and particularly those of olivine in the upper mantle which represent the major mineral phase (see Mainprice and Silver 1993; Barruol and Kern, 1996). Teleseismic shear wave splitting may be used to measure the upper mantle fabric (e.g., Barruol and Souriau, 1995; Barruol et al. 1997) and to get informations on the deep lithosphere structure and mechanical behavior (Vauchez and Barruol, 1996; Vauchez et al, 1997). The anisotropy results obtained on the Kaapval craton (Vinnik et al, 1991) has been related either to an
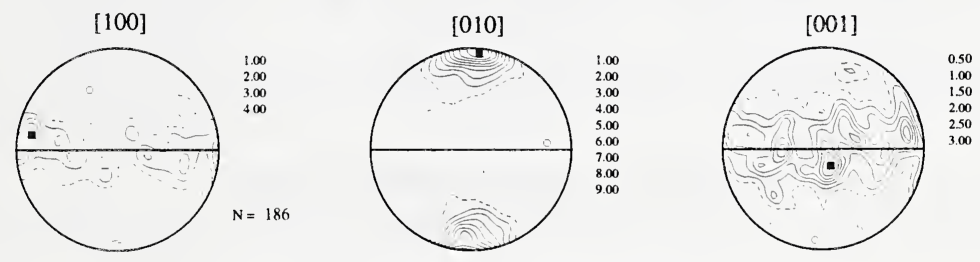

[100] // to X (FRB1309 PREMIER MINE)

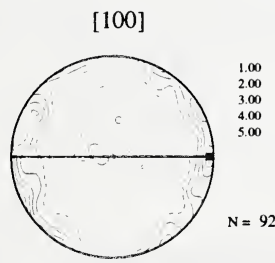

[010]

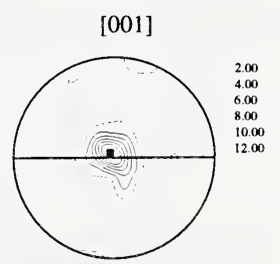

[001] // Y (PHN4254 LOUWRENCIA)

\section{Two typical Olivine lithospheric fabrics of the Kaapval craton}

asthenospheric flow or a frozen lithospheric fabric (Silver, 1996). In order to quantify the anisotropy and constrain the origin of SKS shear wave splitting results that will be acquired during the seismological, NSF funded, Kaapval project, we have built a three-dimensional model of lithospheric mantle seismic properties beneath this craton by characterizing the physical properties of peridotites 
nodules from their lattice preferred orientation (or fabric) of their constituent minerals and the single crystal anisotropic elastic properties.

We report anisotropy logs from 10 kimberlite pipes of the Kaapval craton, at widely spread sample sites. 33 nodules with granular textures, typical of the subcontinental lithosphere have been selected on the basis of modal composition, microstructure and estimated depth origin. The samples display two kinds of olivine LPO (see Figure above); a normal fabric with [100] axes parallel to lineation, marked by the E-W line in the diagram, (which represents about $85 \%$ of our nodules) and a strong abnormal fabric with [001] axes perpendicular to the lineation in the foliation plane. The first fabric is classically attributed to plastic deformation of olivine. The second could result from recrystallisation processes.

An unexpected conclusion is that despite variations in composition, LPO, depth of sampling, localisation on the craton and microtextures, the calculated seismic properties are rather homogeneous. This suggests that the seismic anisotropy is pervasive in this upper mantle section. Calculated anisotropy (see the seismic properties of the examples in the Figure below) is in the range 2-6\% for $\mathrm{P}$ waves and $1-4 \%$ for S-waves.
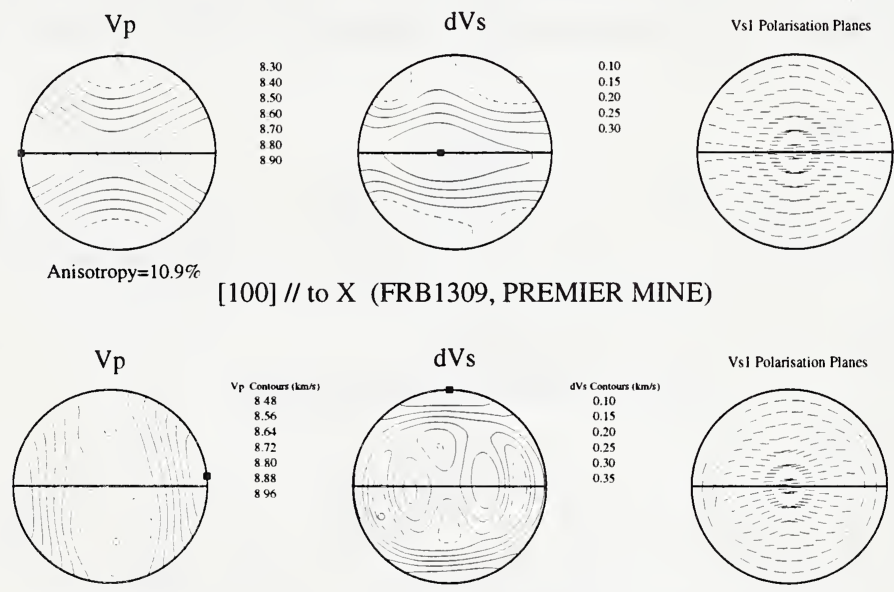

[100] // to X (FRB1309, PREMIER MINE)

Anisotropy $=8.5 \%$
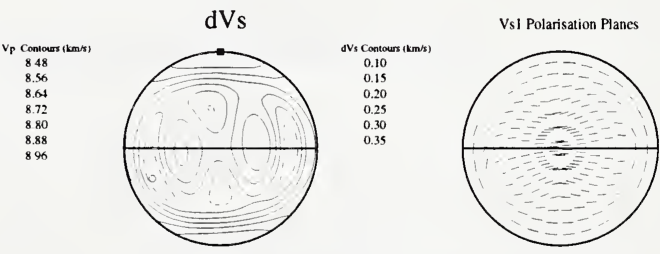

[001] // Y (PHN4254 LOUWRENCIA)

\section{Seismic anisotropy of two typical olivine aggregates of kimberlite nodules from the Kaapval craton}

The average properties of the 33 selected kimberlite nodules, may be used to model SKS splitting observations. For instance, the observed delay times for vertically propagating shear waves (about 1 s) may be explained by a horizontal foliation and an anisotropic layer $120 \mathrm{Km}$ thick, whereas it should be about $220 \mathrm{Km}$ thick for a vertical foliation. 

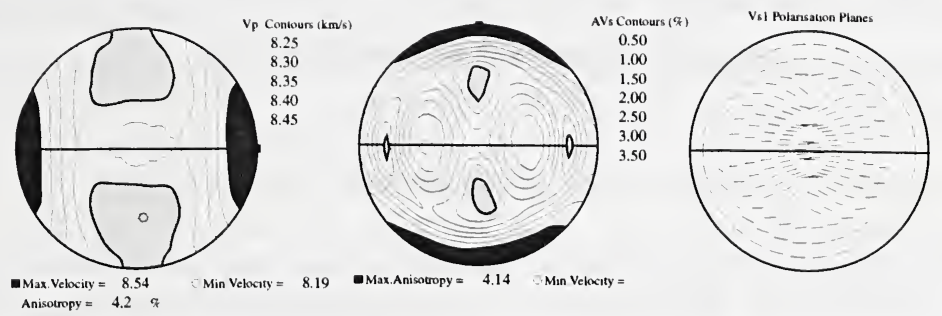

Mean P \& S seismic properties of 33 kimberlite nodules from the Kaapval craton

In all the figures, the black line represents the foliation ( $X Y$ plane), the lineation (X structural direction) is $E-W$ and $Z$ (the pole of the foliation) is NS.

\section{References}

Barruol G. and H. Kern, P and S waves velocities and shear wave splitting in the lower crustal/upper mantle transition (Ivrea Zone). Experimental and calculated data, Phys. Earth Planet. Inter., 95: 175-194, 1996.

Barruol G. and D. Mainprice, A quantitative evaluation of the contribution of crustal rocks to the shear wave splitting of teleseismic SKS waves, Phys. Earth Planet. Inter., 78: 281-300, 1993.

Barruol G., P. G. Silver and A. Vauchez, Seismic anisotropy in the eastern US: deep structure of a complex continental plate, J. Geophys. Res., 102: 8329-8348, 1997.

Barruol G. and A. Souriau, Anisotropy beneath the Pyrenees range from teleseismic shear wave splitting, Geophys. Res. Lett., 22: 493-496, 1995.

Mainprice D. and P. G. Silver, Interpretation of SKS-waves using samples from the subcontinental lithosphere, Phys. Earth Planet. Inter., 78: 257-280, 1993.

Nicolas A. and N. I. Christensen, Formation of anisotropy in upper mantle peridotites - A review, in Composition, Structure and Dynamics of the Lithosphere-Asthenosphere System, Edited by K. Fuchs and C. Froidevaux, Geodyn. Ser. Washington, D.C., AGU. pp 111-123, 1987.

Silver P. G., Seismic anisotropy beneath the continents: probing the depths of the geology, Annu. Rev. Earth Planet. Sci., 24: 385-432, 1996.

Vauchez A. and G. Barruol, Shear wave splitting in the Appalachians and the Pyrenees: Importance of the inherited tectonic fabric of the lithosphere, Phys. Earth Planet. Inter., 95: 127-138, 1996.

Vauchez A., G. Barruol and A. Tommasi, Why do continents break-up parallel to ancient orogenic belts?, Terra Nova, 9: 62-66, 1997.

Vinnik, L.P., Green, R.W.E. and Nicolaysen, L.O., Recent deformation of the deep continental root beneath southern Africa. Nature, 375: 50-52, 1995. 